\title{
Influence of Phosphoric Acid Etching on the Bond Strength of a Universal Adhesive System to Caries-Affected Dentin
}

\author{
Renata Pavanello1* ${ }^{*}$, Sérgio Luiz Pinheiro ${ }^{2}$ \\ ${ }^{1}$ Health Sciences, Pontifícia Universidade Católica de Campinas (PUC-Campinas), Campinas, Brazil \\ ${ }^{2}$ Master's Program in Health Sciences, School of Dentistry, PUC-Campinas, Campinas, Brazil \\ Email: *slpinho@puc-campinas.edu.br, renata_pavanello@yahoo.com.br
}

How to cite this paper: Pavanello, R. and Pinheiro, S.L. (2018) Influence of Phosphoric Acid Etching on the Bond Strength of a Universal Adhesive System to Caries-Affected Dentin. Advances in Biological Chemistry, 8, 37-46.

https://doi.org/10.4236/abc.2018.83004

Received: May 2, 2018

Accepted: June 1, 2018

Published: June 4, 2018

Copyright $\odot 2018$ by authors and Scientific Research Publishing Inc. This work is licensed under the Creative Commons Attribution International License (CC BY 4.0).

http://creativecommons.org/licenses/by/4.0/

\begin{abstract}
The purpose of this study was to evaluate the influence of acid etching on the bond strength of a universal adhesive system (Single Bond Universal, 3M) to caries-affected dentin. Forty permanent third molars were selected and carious lesions were induced by the microbiological method with $S$. mutans ATCC25175. Teeth were allocated randomly across four experimental designs $(\mathrm{n}=10)$ : PA-I: phosphoric acid etching and application of the adhesive system, followed by immediate microtensile bond strength testing; PA-CC: phosphoric acid etching and application of the adhesive system, followed by microtensile bond strength testing after a 14-day cariogenic challenge; NPA-I: application of the adhesive system without acid etching, followed by immediate bond strength testing and NPA-CC: application of the adhesive system without acid etching followed by bond strength testing after 14-day cariogenic challenge. For microtensile bond strength testing, a restoration with Charisma composite resin was made and each specimen was sectioned with a cross-sectional area of $1 \mathrm{~mm}^{2}$. Only adhesive and mixed fractures were considered for bond strength calculation. Results were evaluated by the Kruskal-Wallis and Friedman tests. The highest bond strengths were observed in the phosphoric acid etching groups $(p<0.05)$. Cariogenic challenge did not affect bond strength $(p>0.05)$. The predominant fracture type was adhesive. We conclude that phosphoric acid increased the bond strength of the Single Bond Universal system to caries-affected dentin, and that cariogenic challenge did not interfere with this bond strength.
\end{abstract}

\section{Keywords}

Caries-Affected Dentin, Universal Adhesives, Hybrid Layer, Collagen Fibers, Microtensile Bond Strength 


\section{Introduction}

The minimal intervention dentistry approach is currently advocated for the treatment of carious lesions [1] [2] [3]. The infected, necrotic dentin with irreversibly altered collagen is removed, while affected dentin in which the collagen is amenable to reorganization is kept in the cavity [3]. Histologically, affected dentin consists of dentinal tubules obliterated by acid-resistant crystals during the remineralization process [4] [5].

Recently, universal adhesive systems, which may be applied with or without phosphoric acid etching, have become commercially available [6] [7] [8]. Another important characteristic of these adhesive systems is the presence of MDP (10-methacryloyloxydecyl dihydrogen phosphate) as the functional monomer. This monomer, which has a $\mathrm{pH}$ of 2.7 , is capable of molecular bonding to calcium hydroxyapatite, forming a stable, resistant hybrid layer [9] [10] that reduces nanoleakage [11] [12]. According to Tsuchiya et al. [13], the bonding of MDP to hydroxyapatite helps prevent secondary carious lesions, improves the marginal seal, and enhances the durability of restorations.

Optimal sealing of the cavity enhances the longevity of dental restorations by cutting off the bacterial nutrient supply, thus halting progression of the carious lesion. However, recurrence of caries and postoperative sensitivity may occur due to the presence of viable microorganisms after cavity preparation. A review of the literature carried out for this study did not find any studies comparing the bond strength of the Single Bond Universal adhesive system to caries-affected dentin with or without phosphoric acid preconditioning. The decision to use a universal adhesive system with or without phosphoric acid can influence the adhesion in caries-affected dentin [12] [14]. Within this context, the objective of the present study was to evaluate the influence of phosphoric acid on the bond strength of the Single Bond Universal adhesive system to a carious substrate. The null hypothesis was that phosphoric acid etching would have no significant effect on the bond strength of the Single Bond Universal adhesive system.

\section{Materials and Methods}

The present study was approved by the institutional Research Ethics Committee (protocol no. 722184).

\section{1) Sample selection}

Forty permanent third molars were obtained from a university Dental Clinic.

\section{2) Inclusion criteria}

Erupted permanent third molars; no visible cracks, carious lesions or fractures on inspection with a magnifying glass (10X magnification) were included. The selected teeth were stored in saline solution (Eurofarma, São Paulo, Brazil) and disinfected with 0.1\% thymol (Carcajon, Campinas, Brazil) [15] [16]. A diamond disc (Fava, São Paulo, Brazil) was used to expose the dentin on each specimen. The specimens were sanded with the aid of a polisher and 120- and 240-grit silicon carbide discs (Arotec, Cotia, Brazil), under constant cooling. This was fol- 
lowed by sanding with 400-grit paper (3M, Sumaré, Brazil) for 10 seconds to standardize the smear layer [17]. The teeth were rinsed in running water and stored in saline solution (Eurofarma, São Paulo, Brazil), under refrigeration, until the start of the study.

The apical region of the specimens was sealed with epoxy resin (TecBond, Embu das Artes, Brazil), and the root system and all crown enamel surfaces with nail polish (Impala, Guarulhos, São Paulo). Only the crown dentin was exposed to the cariogenic challenge. The specimens were then autoclaved (Sercon, São Paulo, Brazil) for 15 minutes at $121^{\circ} \mathrm{C}$ and $1 \mathrm{~atm}$.

\section{3) Cariogenic challenge}

To induce carious lesions in the exposed dentin, the teeth were placed in sterile test tubes containing Brain Heart Infusion medium (BHI, Labcenter, São Paulo, Brazil) supplemented with $0.5 \%$ yeast extract (Labcenter, São Paulo, Brazil), $0.5 \%$ glucose (Labcenter, São Paulo, Brazil), and 1\% sucrose (Labcenter, São Paulo, Brazil)and a standard strain of $\mathcal{S}$. mutans ATCC 25175 (Fundação André Tosello, Campinas, Brazil), standardized to $0.5 \mathrm{McF}$ arland turbidity (Labcenter, São Paulo, Brazil).

The specimens were then incubated for 14 days at $37^{\circ} \mathrm{C}$ in anaerobic jars (Labcenter, São Paulo, Brazil), and stored in a bacteriological incubator (Sterilifer, Diadema, Brazil). Throughout the 14-day incubation period, BHI medium was renewed every $24 \mathrm{~h} \mathrm{[15]} \mathrm{[18].} \mathrm{The} \mathrm{pH}$ was measured at every medium change to ensure it was 5 or lower, thus characterizing a cariogenic challenge.

Infected dentin was removed by hand with 320-grit silicon carbide sanding discs (3M, Sumaré, Brazil) until affected dentin was reached-characterized by tissue resistant to penetration by the probe (SSWhite, Juiz de Fora, Brazil) without applying pressure [15].

\section{4) Division of experimental groups}

All samples with carious dentin lesions were randomly allocated (http://www.random.org) across four experimental groups $(\mathrm{n}=10 / \mathrm{each})$. The number of specimens in each group $(\mathrm{n}=10)$ was obtained by sample size calculation after a pilot experiment. Sample size calculation was performed by ANOVA, with a minimum difference between treatment means $=0.38$, standard error $=0.23$, number of treatments $=4$, statistical power $=0.80$, and alpha $=$ 0.05 . The sample size was calculated as 10 .

Group PA-I: etching of affected dentin with 35\% phosphoric acid (Ultradent, South Jordan, UT, USA) for 15 seconds. The specimens were then rinsed and dried with cotton balls, without allowing dehydration. The Single Bond Universal adhesive system (3M ESPE, St Paul, MN, USA) was actively applied with a microbrush (Angelus, Londrina, Brazil) onto the entire dentin surface for 20 seconds. An air jet was then applied over the adhesive for 5 seconds, until the solvent had evaporated. Finally, the adhesive system was light-cured for 10 seconds (VALO-Ultradent, South Jordan, UT, USA). Microtensile bond strength testing was performed immediately.

Group PA-CC: the test specimens were prepared as for the PA-I group, but 
microtensile bond strength testing was performed after a 14-day cariogenic challenge.

Group NPA-I: the Single Bond Universal adhesive system (3M ESPE, St Paul, MN, USA) was actively applied with a microbrush (Angelus, Londrina, Brazil) onto the entire dentin surface for 20 seconds. An air jet was then applied over the adhesive for 5 seconds, until the solvent had evaporated. Finally, the adhesive system was light-cured for 10 seconds (VALO-Ultradent, South Jordan, UT USA). Microtensile bond strength testing was performed immediately.

Group NPA-CC: the test specimens were prepared as for the NPA-I group, but microtensile bond strength testing was performed after a 14-day cariogenic challenge.

After application of the adhesive system (Single Bond Universal, 3M ESPE), a restoration with Charisma composite resin (Heraeus Kulzer, Hanau, Germany) was constructed by the incremental technique atop the dentin surface, in four layers, each approximately $1 \mathrm{~mm}$ high, light-cured for $40 \mathrm{~s}$ each, until a total height of $3 \mathrm{~mm}$ was reached. The composite resin increments were measured with a digital caliper (Mitutoyo, Suzano, Brazil). The curing light used in this study (Valo, Ultradent, South Jordan, UT, USA) had an intensity of 1000 $\mathrm{mW} / \mathrm{cm}^{2}$, checked with a radiometer (Curing Light, Brasilia, Brazil).

5) Obtaining the specimens for microtensile bond strength testing

For microtensile bond strength testing, the root portion of each tooth was removed with diamond discs (Fava, São Paulo, Brazil). Each tooth/adhesive/resin block was cut with diamond discs on an Isomet 1000 precision sectioning saw (Buehler, Illinois, USA), into parallel slices following the long axis of the tooth, in the lingual-lingual direction. These slices were again attached to an acrylic plate and taken back to the Isomet 1000 precision cutter (Buehler, Illinois, USA), with a pre-set cutting width of $1.3 \mathrm{~mm}$, so that the resulting stick-shaped specimens would have an area of approximately $1.0 \mathrm{~mm}^{2}$.

Before microtensile bond testing, the width and thickness of each specimen were confirmed with a digital caliper (Mitutoyo, Suzano, Brazil; accuracy 0.01 $\mathrm{mm})$. Forty-four specimens were obtained from each group.

\section{6) Microtensile bond strength test}

The ends of the specimens were attached to the microtensile assay device (Geraldeli jig) with cyanoacrylate glue (Loctite, Henkel Ltda., São Paulo, SP, Brazil), so as to keep the adhesive area perpendicular to the long axis of the tensile force [6].

The jig was then taken to a universal testing machine (EMIC, São José dos Pinhais, Brazil) and run with a crosshead speed of $0.5 \mathrm{~mm} / \mathrm{min}$ until fracture occurred [19] At the instant of fracture, the load in Newtons (N) recorded and the specimen examined under a 40X stereo microscope (Tecnival, São Paulo, Brazil) to ascertain the fracture mode (adhesive, cohesive dentin, cohesive resin, or premature). Only specimens with adhesive/mixed (interface) fractures were used for microtensile bond strength calculation [6]. The fracture load of each 
specimen was divided by its bonding area. For analysis of fracture mode findings, the following scores were assigned:

Score 1: premature fracture;

Score 2: adhesive fracture;

Score 3: cohesive dentin fracture;

Score 4: cohesive resin fracture.

All results were obtained in Newtons $(\mathrm{N})$ and converted to megapascals (MPa) by the following formula:

$$
B S=\frac{F}{S} * 0.0981
$$

where $B S=$ bond strength; $F=$ force in Newtons; $S=$ bond surface area of the specimen $\left(\mathrm{cm}^{2}\right) ; 0.09801=$ correction factor for conversion of $\mathrm{kp} / \mathrm{cm}^{2}$ into MPa.

\section{7) Statistical analysis}

The results were analyzed in Biostat 4.0. D'Agostino's test showed that the sample departed from normality. Thus, the Kruskal-Wallis non-parametric test (with Student-Newman-Keuls post-hoc test) and Friedman test were used. The significance level was set at $5 \%$.

\section{Results}

The highest bond strengths were observed in the groups in which phosphoric acid etching preceded application of the self-etching adhesive system $(p<0.05)$. There was no significant difference in bond strength before (immediate testing) and after cariogenic challenge $(p>0.05)$ (Table 1$)$.

\section{Analysis of fracture mode}

There was no significant difference in fracture mode across sample groups $(p>0.05)$ (Table 2).

\section{Discussion}

Contemporary dentistry advocates a minimally invasive approach to cavity preparations removing infected dentin while preserving caries-affected dentin that is amenable to reorganization [15] [20] [21] [22] [23]. The methodology of

Table 1. Descriptive analysis: Minimum (Min), maximum (Max), median (Md), interquartile range (IQR), and Kruskal-Wallis statistic (with Student-Newman-Keulspost-hoc test) for each sample group (MPa).

\begin{tabular}{ccccc}
\hline & PA-I & PA-CC & NPA-I & NPA-CC \\
\hline Min & 10.25 & 10.20 & 2.22 & 0 \\
Max & 44.37 & 58.89 & 48.73 & 82.84 \\
Md (IQR) & $24.30(11.98)^{\mathrm{A}}$ & $27.10(21.97)^{\mathrm{A}}$ & $15.31(23.07)^{\mathrm{B}}$ & $14.93(20.91)^{\mathrm{B}}$ \\
\hline
\end{tabular}

Different letters denote significant differences $(p<0.05)$. PA-I, phosphoric acid etching followed by immediate testing; PA-CC, phosphoric acid etching followed by testing only after cariogenic challenge; NPA-I, immediate testing with no phosphoric acid etching; NPA-CC, testing only after cariogenic challenge, with no phosphoric acid etching. 
Table 2. Descriptive analysis: minimum (Min), maximum (Max), median (Md), interquartile range (IQR), and Friedman test.

\begin{tabular}{ccccc}
\hline & PA-I & PA-CC & NPA-I & NPA-CC \\
\hline Max & 2.0 & 2.0 & 2.0 & 2.0 \\
Min & 2.0 & 2.0 & 2.0 & 1.0 \\
Md (IQR) & $2.0(0.0)^{\mathrm{A}}$ & $2.0(0.0)^{\mathrm{A}}$ & $2.0(0.0)^{\mathrm{A}}$ & $2.0(0.0)^{\mathrm{A}}$ \\
\hline
\end{tabular}

Same letters: No significant differences $(p>0.05)$.

this study used affected dentin as a substrate for bond strength testing, a design consistent with previous work by Nakajima et al. [24], Yoshiyama et al. [2]. Arrais et al. [25], Erhardt et al. [5], De Carvalho et al. [26], Carvalhoet al. [27], Scheffel et al. [3], Becci et al. [15], Lenzi et al. [4], Mattos et al. [28], and Li et al. [29].

In the present study, the microbiological method was used to induce dentinal caries [3] [18] [23] by challenge with a $S$. mutans and supplemented culture medium. The microbiological cariogenic challenge was used in this study to reproduce the characteristics found in natural carious dentin, such as discoloration and changes in texture [1] [4] [26] [27] [30]. Shibata et al. [14] and Sattabanasuk et al. [20] reported the need for standardization of the method used to remove carious lesions in studies seeking to evaluate the bond strength of adhesive systems. In the present study, infected dentin was removed while affected dentin was preserved by using the standard method described by Arrais et al. [25], Becci et al. [15], and Scheffel et al. [3]. Infected dentin was worn down with 320-grit15 silicon carbide sandpaper until resistance to manual pressure with a dental explorer was encountered.

Bond strength was evaluated with a microtensile test [4] [6] [12] [19] [21] [24] [25] [26] [31] [32]. Stick-shaped specimens with a cross-sectional area of approximately $1 \mathrm{~mm}^{2}$ were obtained for better stress distribution during the test, in an attempt to reduce the number of cohesive failures, as is common in the shear test [33].

To evaluate the longevity of the bond strength of the Single Bond Universal adhesive system, the specimens were subjected to a cariogenic challenge, i.e., a 14-day stress period in supplemented BHI medium. In the literature, samples have usually been stored in distilled water [5] [31] [32] or artificial saliva for assessment of bond-strength longevity [17]. In the present study, however, specimens restored with composite resin were exposed to a microbiological cariogenic challenge with the objective of simulating what happens to composite resin restorations in the oral cavity of patients with recurrent caries. Our literature did not find any previous studies with a similar methodology.

The results of the present investigation demonstrated that phosphoric acid etching enhanced the bond strength of the universal adhesive system to affected dentin. The null hypothesis was not accepted. This is in agreement with the findings of Yoshiyama et al. [2], Ceballos et al. [34], Arrais et al. [25], Li et al. [29], Aggarwal et al. [35], and Naik et al. [36]. Caries-affected dentin is characte- 
rized by occlusion and ultimately obliteration of the dentinal tubules by acid-resistant crystals; application of phosphoric acid solubilizes these intratubular mineral deposits, increasing the permeability of dentin and, consequently, improving penetration of the adhesive agent.

Bond strength was lower when acid etching was not employed. This is consistent with the findings of Pinna et al. [37], who reported that self-etching adhesives fail to effectively penetrate dentinal tubules occluded by the carious process, and of Ceballos et al. [34] and Arrais et al. [25], who noted that the acid monomer present in the self-etching adhesive system is not enough to dissolve the mineral deposits found in caries-affected dentin and allow penetration of the adhesive system. Arrais et al. [25] reported that this is an inefficient pH for penetration of the adhesive agent into caries-affected dentin. Regarding fracture patterns in the present study, adhesive-type fractures were predominant; this corroborates the findings of Shibata et al. [14] in caries-affected dentin. Only the group of specimens subjected to cariogenic stress without phosphoric acid etching exhibited premature fractures (20\%). This is consistent with the findings of Scholtanus et al. [38], who reported that this fracture mode is attributable to intrinsic failures of the dental substrate and composite resin material. The difficulty of penetration by the adhesive system caused by obliteration of caries-affected dentinal tubules and compounded by the carioenic stress probably explains the percentage of premature fractures in this group [2] [25] [34].

Within the limitations of an in vitro design, the present study demonstrated that, in caries-affected dentin, a substrate characterized by obliteration of dentinal tubules and altered mineral content, the use of phosphoric acid etching prior to application of the Single Bond Universal adhesive system was associated with better results. However, additional studies in this line of research are needed to contribute further scientific evidence on this matter.

\section{Conclusions}

We conclude that:

Phosphoric acid etching increased the bond strength of the Single Bond Universal adhesive system to caries-affected dentin; and the pattern of fracture was predominant adhesive.

Cariogenic challenge did not interfere with bond strength.

\section{References}

[1] Azevedo, C.S., Trung, L.C., Simionato, M.R., Freitas, A.Z. and Matos, A.B. (2011) Evaluation of Caries-Affected Dentin with Optical Coherence Tomography. Brazilian Oral Research, 25, 407-413. https://doi.org/10.1590/S1806-83242011000500006

[2] Yoshiyama, M., Tay, F.R., Doi, J., Nishitani, Y., Yamada, T., Itou, K., Carvalho, R.M., Nakajima, M. and Pashley, D.H. (2002) Bonding of Self-Etch and Total-Etch Adhesives to Carious Dentin. Journal of Dental Research, 81, 556-560. https://doi.org/10.1177/154405910208100811

[3] Scheffel, D.L., Ricci, H.A., de Souza Costa, C.A., Pashley, D.H. and Hebling, J. 
(2013) Effect of Reducing Acid Etching Time on Bond Strength to Noncarious and Caries-Affected Primary and Permanent Dentin. Pediatric Dentistry, 35, 199-204.

[4] Lenzi, T.L., Calvo, A.F., Tedesco, T.K., Ricci, H.A., Hebling, J. and Raggio, D.P. (2015) Effect of Method of Caries Induction on Aged Resin-Dentin Bond of Primary Teeth. BMC Oral Health, 15, 79. https://doi.org/10.1186/s12903-015-0049-z

[5] Erhardt, M.C., Toledano, M., Osorio, R. and Pimenta, L.A. (2008) Histomorphologic Characterization and Bond Strength Evaluation of Caries-Affected Dentin/Resin Interfaces: Effects of Long-Term Water Exposure. Dental Materials, 24, 786-798. https://doi.org/10.1016/j.dental.2007.09.007

[6] Munoz, M.A., Luque, I., Hass, V., Reis, A., Loguercio, A.D. and Bombarda, N.H. (2013) Immediate Bonding Properties of Universal Adhesives to Dentine. Journal of Dentistry, 41, 404-411. https://doi.org/10.1016/j.jdent.2013.03.001

[7] Luque-Martinez, I.V., Perdigao, J., Munoz, M.A., Sezinando, A., Reis, A. and Loguercio, A.D. (2014) Effects of Solvent Evaporation Time on Immediate Adhesive Properties of Universal Adhesives to Dentin. Dental Materials, 30, 1126-1135. https://doi.org/10.1016/j.dental.2014.07.002

[8] Sofan, E., Sofan, A., Polaia, G., Tenore, G., Romeo, U. and Miglian, G. (2017) Classification Review of dental Adhesive Systems: From the IV Generation to the Universal Type. Annali Di Stomatologia (Roma), 8, 1-17. https://doi.org/10.11138/ads/2017.8.1.001

[9] Yoshida, Y., Yoshihara, K., Nagaoka, N., et al. (2012) Self-Assembled Nano-Layering at the Adhesive Interface. Journal of Dental Research, 91, 376-381. https://doi.org/10.1177/0022034512437375

[10] Perdigao, J. and Swift Jr., E.J. (2015) Universal Adhesives. Journal of Esthetic and Restorative Dentistry, 27, 331-334. https://doi.org/10.1111/jerd.12185

[11] Yoshihara, K., Nagaoka, N., Okihara, T., et al. (2015) Functional Monomer Impurity Affects Adhesive Performance. Dental Materials, 31, 1493-1501. https://doi.org/10.1016/j.dental.2015.09.019

[12] Nicoloso, G.F., Antoniazzi, B.F., Lenzi, T.L., Soares, F.Z.M. and Rocha, R.O. (2016) Is There a Best Protocol to Optimize Bond Strength of a Universal Adhesive to Artificially Induced Caries-Affected Primary or Permanent Dentin? The Journal of Adhesive Dentistry, 18, 441-446.

[13] Tsuchiya, K., Takamizawa, T., Barkmeier, W.W., Tsubota, A.T., Berry, T.P., Erickson, R.L., Latta, M.A. and Miyazaki, M. (2016) Effect of a Functional Monomer (MDP) on the Enamel Bond Durability of Single-Step Self-Etch Adhesives. European Journal of Oral Sciences, 124, 96-102. https://doi.org/10.1111/eos.12232

[14] Shibata, S., Vieira, L.C., Baratieri, L.N., Fu, J., Hoshika, S., Matsuda, Y. and Sano, H. (2016) Evaluation of Microtensile Bond Strength of Self-Etching Adhesives on Normal and Caries-Affected Dentin. Dental Materials Journal, 35, 166-173. https://doi.org/10.4012/dmj.2014-330

[15] Becci, A.C.O., Marti, L.M., Zuanon, A.C., Brighenti, F.L., Spolidório, D.M.P. and Giro, E.M.A. (2016) Influence of the Addition of Chlorhexidine Diacetate on Bond Strength of a High-Viscosity Glass Ionomer Cement to Sound and Artificial Caries-Affected Dentin. American Journal of Dentistry, 29, 277-281.

[16] Ziskind, D., Gleitman, J., Rotstein, I. and Friedman, M. (2003) Evaluation of Cetylpyridium Chloride for Infection Control in Storage Solution. Journal of Oral Rehabilitation, 30, 477-481. https://doi.org/10.1046/j.1365-2842.2003.01091.x

[17] Marchesi, G., Frassetto, A., Mazzoni, A., Apolonio, F., Diolosa, M., Caderano, M., Di Lenarda, R., Pashley, D.H., Tay, F. and Breschi, L. (2014) Adhesive Performance 
of a Multi-Mode Adhesive System: 1-Year in Vitro Study. Journal of Dentistry, 42, 603-612. https://doi.org/10.1016/j.jdent.2013.12.008

[18] Carvalho, F.G., Fucio, S.B.P., Sinhoreti, M.A.C., Correr-Sobrinho, L. and Puppin-Rontani, R.M. (2008) Confocal Laser Scanning Microscopic Analysis of the Depth of Dentin Caries-Like Lesion in Primary and Permanent Teeth. Brazilian Dental Journal, 19, 139-144. https://doi.org/10.1590/S0103-64402008000200010

[19] Gre, C.P., Andrada, M.A.C. and Monteiro Junior, S. (2016) Microtensile Bond Strength of a Universal Adhesive to Deep Dentin. Brazilian Dental Science, 19, 1259. https://doi.org/10.14295/bds.2016.v19i2.1259

[20] Sattabanasuk, V., Burrow, M.F., Shimada, Y. and Tagami, J. (2006) Resin Adhesion to Caries-Affected Dentine after Different Removal Methods. Australian Dental Journal, 51, 162-169. https://doi.org/10.1111/j.1834-7819.2006.tb00421.x

[21] Joves, G.J., Inoue, G., Nakashima, S., Sadr, A., Nikaido, T. and Tagami, J. (2013) Mineral Density, Morphology and Bond Strength of Natural versus Artificial Caries-Affected Dentin. Dental Materials Journal, 32, 138-143.

https://doi.org/10.4012/dmj.2012-243

[22] Mount, G.J. (2011) Minimal Intervention in Dentistry. Journal of Minimum Intervention in Dentistry, 4, 102-104.

[23] Costa, A.R., Garcia-Godoy, F., Correr-Sobrinho, L., Naves, L.Z., Raposo, L.H., Carvalho, F.G., Sinhoreti, M.A. and Puppin-Rontani, R.M. (2017) Influence of Different Dentin Substrate (Caries-Affected, Caries-Infected, Sound) on Long-Term muTBS. Brazilian Dental Journal, 28, 16-23. https://doi.org/10.1590/0103-6440201700879

[24] Nakajima, M., Sano, H., Burrow, M.F., Tagami, J., Yoshiama, M., Ebisu, S., Ciucchi, B., Russell, C.M. and Pashley, D.H. (1995) Tensile Bond Strength and SEM Evaluation of Caries-Affected Dentin Using Dentin Adhesives. Journal of Dental Research, 74, 1679-1688. https://doi.org/10.1177/00220345950740100901

[25] Arrais, C.A., Giannini, M., Nakajima, M. and Tagami, J. (2004) Effects of Additional and Extended Acid Etching on Bonding to Caries-Affected Dentine. European Journal of Oral Sciences, 112, 458-464. https://doi.org/10.1111/j.1600-0722.2004.00159.x

[26] De Carvalho, F.G., Puppin-Rontani, J., Dos Santos, R.L., Carlo, H.L., Bonan, P.R., Garcia-Godoy, F. and Puppin-Rontani, R.M. (2014) In Vitro Effect of S. mutans Biofilm on Fluoride/MDPB-Containing Adhesive System Bonded to Caries-Affected Primary Dentin. American Journal of Dentistry, 27, 227-232.

[27] Carvalho, C., Fernandes, F.P., Freitas, V.P., França, F.M., Basting, R.T., Turssi, C.P. and Amaral, F.L. (2016) Effect of Green Tea Extract on Bonding Durability of an Etch-and-Rinse Adhesive System to Caries-Affected Dentin. Journal of Applied Oral Science, 24, 211-217. https://doi.org/10.1590/1678-775720150518

[28] Mattos, A.B., Azevedo, C.S., Trevelin, L.T. and Aranha, A.C.C. (2016) Adhesion of a Selth-Etching Adhesive to Caries-Affected Dentin Treated with Different Methods for Caries Removal: A Preliminary Study. Brazilian Dental Science, 19, 1285.

[29] Li, H., Wang, W.M., Yu, S.L. and Wen, Q. (2011) Morphological and Microtensile Bond Strength Evaluation of Three Adhesive Systems to Caries-Affected Human Dentine with Chemomechanical Caries Removal. Journal of Dentistry, 39, 332-339. https://doi.org/10.1016/j.jdent.2011.02.004

[30] Marquezan, M., Corrêa, F.N.P., Sanabe, M.E., Rodrigues Filho, L.E., Hebling, J., Guedes-Pinto, A.C. and Mendes, F.M. (2009) Artificial Methods of Dentine Caries Induction: A Hardness and Morphological Comparative Study. Archives of Oral Biology, 54, 1111-1117. https://doi.org/10.1016/j.archoralbio.2009.09.007 
[31] Manfroi, F.B., Marcondes, M.L., Somacal, D.C., Borges, G.A., Junior, L.H. and Spohr, A.M. (2016) Bond Strength of a Novel One Bottle Multi-Mode Adhesive to Human Dentin after Six Months of Storage. The Open Dentistry Journal, 10, 268-277. https://doi.org/10.2174/1874210601610010268

[32] Takamizawa, T., Barkmeier, W.W., Tsujimoto, A., Berry, T.P., Watanabe, R.L., Latta, M.A. and Miyazaki, M. (2016) Influence of Different Etching Modes on Bond Strength and Fatigue Strength to Dentin Using Universal Adhesive Systems. Dental Materials, 32, e9-e21. https://doi.org/10.1016/j.dental.2015.11.005

[33] Mushtag, E.A., Mathai, V., Nair, R.S. and Angelo, J.M.C. (2017) The Effect of a Dentin Desensitizer on the Shear Bond Strength of Composite to Dentin Using Three Different Bonding Agents: An in Vitro Study. Journal of Conservative Dentistry, 20, 37-40. https://doi.org/10.4103/0972-0707.209069

[34] Ceballos, L., Camejo, D.G., Victoria Fuentes, M., Osorio, R., Toledano, M., Carvalho, R.M. and Pashley, D.H. (2003) Microtensile Bond Strength of Total-Etch and Self-Etching Adhesives to Caries-Affected Dentine. Journal of Dentistry, 31, 469-477. https://doi.org/10.1016/S0300-5712(03)00088-5

[35] Aggarwal, V., Singla, M., Yadav, S. and Yadav, H. (2013) The Effect of Caries Excavation Methods on the Bond Strength of Etch-and-Rinse and Self-Etch Adhesives to Caries Affected Dentine. Australian Dental Journal, 58, 454-460.

https://doi.org/10.1111/adj.12121

[36] Naik, S.V., Shashikiran, N.D., Chaitra, N.L. and Syed, G. (2014) A Microtensile Bond Strength Evaluation of a Single-Bottle Adhesive to Caries-Affected Dentin in Conventional versus Minimal Invasive Caries Removal Techniques: An In-Vitro Study. Indian Journal of Dentistry, 5, 127-131. https://doi.org/10.4103/0975-962X.140821

[37] Pinna, R., Maioli, M., Eramo, S., Mura, I. and Milia, E. (2015) Carious Affected Dentine: Its Behaviour in Adhesive Bonding. Australian Dental Journal, 60, 276-293. https://doi.org/10.1111/adj.12309

[38] Scholtanus, J.D., Purwanta, K., Dogan, N., Kleverlaan, C.J. and Felizier, A.J. (2010) Microtensile Bond Strength of Three Simplified Adhesive Systems to Caries Affected Dentin. The Journal of Adhesive Dentistry, 12, 273-278. 